\title{
Delirium-Related Knowledge, Caregiving Performance, Stress Levels, and Mental Health of Family Caregivers of Terminal Cancer Patients with Delirium in a Hospice Care Unit
}

\author{
Mi Hyun Jung, A.P.N., M.S.N., Myung-Hee Park, A.P.N., Ph.D., \\ Su-Jeong Kim, R.N. and Jeong Ran Ra, A.P.N., Ph.D. \\ Hospice \& Palliative Care Center, Seoul St. Mary's Hospital, University of Catholic, Seoul, Korea
}

Purpose: The purpose of this study was to examine the knowledge, caregiving performance, stress levels, and mental health of family caregivers of terminal cancer patients with delirium, insofar as these characteristics are relevant for delirium. Methods: Between May 1, 2019, and June 1, 2020, 96 family caregivers of terminal cancer patients with delirium completed a structured survey, the results of which were analyzed. Results: The average correct answer rate for delirium-related knowledge was 53.2\% across all subcategories, which included knowledge of causes (41.5\%), symptoms (65.4\%), and caregiving (51.7\%). The average score for family caregivers' performance of caregiving for delirium was 2.60 \pm 0.5 , with subcategories including caregiving for patients without delirium (2.16 \pm 0.95$)$, caregiving for patients with delirium $(2.84 \pm 1.01)$, and stress related to caregiving for delirium (39.88 \pm 16.55$)$, as well as categories such as patient-related caregiving (44.32 \pm 28.98$)$, duty-related caregiving $(44.21 \pm 30.15)$, and interpersonal relationship-related caregiving (22.35 \pm 25.03$)$. For mental health, the average score among family caregivers was $1.96 \pm$ 0.70 , with the highest score being for the category of additional items $(2.28 \pm 0.84)$. Family caregivers of patients with hyperactive delirium as the delirium subtype had higher scores for caregiving performance than caregivers of patients with mixed delirium. Conclusion: Scores for the delirium-related knowledge and caregiving performance of family caregivers were low, while their caregiving stress levels were high due to their lack of knowledge and experience. This indicates the importance of delirium-related education for family members of patients with delirium and the necessity of developing nursing intervention programs to help manage stress and promote mental health among family caregivers.

Key Words: Delirium, Caregivers, Knowledge, Work performance, Psychological stress, Mental health
Received December 28, 2020

Revised March 24, 2021

Accepted April 1, 2021
Correspondence to

Myung-Hee Park

ORCID:

https://orcid.org/0000-0002-7256-8151

E-mail:agathapark@cmcnu.or.kr

\section{INTRODUCTION}

\section{Background}

Delirium entails acute confusion, nervousness, a decline in one's ability to concentrate, and cognitive disorder. It is a neuropsychiatric disorder that exhibits constantly changing degrees of symptoms, often within a single day, and with fluctuations that tend to be short-lived [1]. While delirium is very common and difficult for terminal cancer patients, it 
can be overlooked and receive insufficient treatment, causing more suffering for the patients [2]. The prevalence of delirium in the fields of hospice and palliative care varies from $13 \%$ to $88 \%$ depending on the patients, how advanced the disease is, the instruments used to measure delirium, and diagnosis standards. The prevalence of delirium is also higher than the prevalence of admission to acute-phase wards, which ranges from $20 \%$ to $27 \%$ [3]. There tends to be a delay in addressing delirium after its onset, as patients may not be able to explain their symptoms properly [4], resulting in patients missing the window during which they can determine the direction of their treatment by themselves and spend their last moments settling affairs with their families. This aggravates stress not only for patients but also their families, adding to their care burdens [5].

Due to the culture of medical practice in South Korea, in which medical personnel are typically unable to observe patients 24 hours a day due to the severity of patients' conditions and the heavy workloads faced by staff, patients' families take on an important role in managing delirium [6]. The family understands the patient's normal mental state, cognitive capacity, and behaviors, so they can register subtle changes in cognitive function resulting from delirium. However, in many cases, a patient's family does not have accurate information about delirium and often believes a patient's changed mental state is due to dementia or aging, which leads to a failure to address the condition in a timely manner $[7,8]$.

Delirium tends to be a very painful experience for the family, especially when patients behave aggressively. A patient's family can experience certain negative emotions like fear, confusion, guilt, rage, or sorrow [9]. Not knowing the reason for delirium also tends to scare families [5]. Families of patients suffering from delirium are 12 times more likely to suffer from generalized anxiety disorder, according to one study [10]. Many families of patients feel powerless due to the patient's delirium and show concern for the patient's well-being [5].

While the prevalence of delirium among terminal cancer $\mathrm{pa}^{-}$ tients is higher than it is among patients of other diseases, most studies about delirium examined patients in general wards rather than hospice wards. In addition, many studies focused on nurses and caregivers [11-13]. Moreover, most studies on delirium undertaken in the field of hospice and palliative care are about the prevalence of delirium, risk factors, utilization of diagnostic instruments, and the condition's impact on survival estimates $[14,15]$.

Hence, this study aimed to examine the perceptions of families of terminal cancer patients with delirium admitted to hospice wards regarding their knowledge, caregiving performance, stress levels, and mental health, as these characteristics are relevant for delirium. The results of this study may be used as a fundamental resource for developing educational materials to improve families' awareness of caregiving for delirium and to enhance their ability to respond to delirium.

\section{Purpose}

The purpose of this study was to examine the knowledge, caregiving performance, stress levels, and mental health of family members of terminal cancer patients with delirium, insofar as these factors are relevant for delirium. In more detail, the objectives were:

1) To compare the general characteristics and characteristics related to conditions between patients with delirium and without delirium.

2) To examine the general and caregiving-related characteristics of patients' families.

3) To examine families' knowledge, caregiving performance, stress levels, and mental health as they pertain to delirium.

4) To perform a comparative analysis of the general characteristics of families, characteristics related to caregiving, and families' knowledge of delirium based on patients' subtypes of delirium, as well as caregiving performance, stress levels, and mental health as they pertain to delirium.

\section{METHODS}

\section{Study design}

This descriptive survey study examined the knowledge, caregiving performance, stress levels, and mental health of family members of terminal cancer patients with delirium, as these factors are relevant for delirium.

\section{Participants}

The participants of this study were family members of terminal cancer patients admitted to the hospice and palliative 
care ward of S Hospital between May 1, 2019, and June 1, 2020, who were diagnosed with delirium on admission using the Korean version of the Delirium Rating Scale (K-DRS-98). Family members of patients who were admitted in the endof-life course, however, or who were admitted for a second time were excluded.

The sample size was determined with $G^{*}$ Power 3.1.9.2. The sample size was calculated to be $\mathrm{N}=90$ or higher, with the effect size of analysis of variance (ANOVA) set at an intermediate level with a 0.05 level of significance and power $(1-\beta)$ of 0.80 . For this study, 100 participants were selected after accounting for an expected $10 \%$ attrition rate.

In total, 425 patients were admitted to the hospital during the period of study. 121 patients were admitted for end-of-life care, and 33 did not have a caregiver or refused to take part in the study and were excluded. Of the remaining $271 \mathrm{pa}^{-}$ tients, 100 patients were diagnosed with delirium using the $\mathrm{K}-$ DRS-98 instrument. Patients who were admitted during the aforementioned period were classified into two groups (those with delirium and those without delirium) and analyzed. Questionnaires were distributed to the caregivers of patients with delirium. Ultimately, 96 responses, after excluding four responses with insufficient answers, were included in the data analysis.

\section{Study tools}

\section{1) General and clinical characteristics of patients and their families, and characteristics related to caregiving}

The demographic and clinical characteristics of the patients included five items: sex, age, cancer type, ability to perform daily routines, and cognitive function. Demographic characteristics and characteristics related to caregiving of patients' family members included eight items: sex, age, education level, relationship with the patient, degree of assistance from other family members, duration of caregiving, health status, and experience with delirium education.

\section{2) Delirium}

Delirium was assessed using the K-DRS-98, which was originally developed by Trzepacz et al. [16] and revised and supplemented by Lim et al. [17]. The K-DRS-98 contains 13 items for assessing delirium severity and three diagnostic items.
The items for assessing severity included statements about sleep-wake cycle disturbance, perceptual disturbances and hallucinations, delusions, lability of affect, language, thought process abnormalities, motor agitation, and motor retardation. In addition, there were five items for assessing severity that targeted cognitive functions in particular, which included statements about orientation, attention, short-term memory, long-term memory, and visuospatial ability. Diagnostic items included statements on the temporal onset of symptoms, fluctuation of symptom severity, and physical disorder. Severity items were rated on a scale from 0 to 3 and diagnostic measures on a scale from 0 to 2 or 0 to 3 , with a higher total score indicating more severe delirium. The maximum possible score for all 16 items was 46, and the maximum score for the severity items alone was 39 . The cut-off values of the K-DRS-98 for the severity score alone and the total score were 16 and 21.5, respectively. The subtype of delirium was evaluated using items 7 (motor agitation) and 8 (motor retardation). Patients were considered to have the hyperactive subtype of delirium if their score for item 7 ranged from 1 to 3 and their score for item 8 was 0 . Patients were considered to have the hypoactive subtype if their score for item 8 ranged from 1 to 3 and their score for item 7 was 0 . If patients scored a 1 or higher for both items 7 and 8, they were considered to have the mixed subtype. Lastly, if patients scored a 0 for both items 7 and 8, they were considered to have no motor subtype. When the instrument was developed, its Cronbach's $\alpha$ was $0.86 \sim 0.87$. In this study, it was 0.81 .

\section{3) Knowledge of caregiving for delirium}

Knowledge of caregiving for delirium was measured using an instrument developed by Jeong [18] targeting caregivers. The instrument included 25 questions in total. Seven questions covered the causes of delirium, eight addressed symptoms, and 10 assessed caregiving practices. Each question was answered with "yes", "no", or "I don't know." Correct answers were assigned 1 point and other answers were assigned 0 points. The maximum possible score was 25 points, with a higher score representing a higher degree of knowledge. At the time of the tool's development, Cronbach's $\alpha$ was 0.70 . In this study, it was 0.74 . 


\section{4) Performance of caregiving for delirium}

Performance of caregiving for delirium was measured using an instrument developed by Jeong [18] to assess caregivers. It included 25 questions. Eight questions were about pre-onset caregiving and 17 were about post-onset caregiving. Each question was rated on 4-point Likert scale, with 4 points indicating "always", 3 points indicating "frequently", 2 points indicating "sometimes", and 1 point indicating "rarely." A higher score indicated a higher quality of caregiving for delirium. Cronbach's $\alpha$ was 0.87 at the time of the tool's development, and it was 0.87 for this study.

\section{5) Stress related to caregiving for delirium}

Stress related to caregiving for delirium was measured using an instrument developed by Jeong [18] to assess caregivers consisting of 20 questions. Seven questions were related to patients, nine were related to duties, and four were related to interpersonal relationships. Respondents were asked to rate each question on a 100 -point scale, with 0 points indicating no stress and 100 points indicating extreme stress. A higher score indicated a higher degree of stress. Cronbach's $\alpha$ was 0.90 at the time of the tool's development, and it was 0.89 for this study.

\section{6) Mental health status}

Mental health status was evaluated using an instrument created by Kim et al. [19]. The instrument was created by standardizing a Korean version of the Symptom Checklist90-Revised (SCL-90-R) developed by Derogatis et al. [20]. The SCL-90-R is a self-reported multi-dimensional symptom checklist test with 90 questions covering the following nine categories: somatization, obsessive-compulsive, interpersonal sensitivity, depression, anxiety, hostility, phobic anxiety, paranoid ideation, and psychoticism. It has 83 items covering these categories and seven additional items. Additional questions feature assessment items for systemic symptoms that were not included among the nine psychotic symptom categories, such as appetite, sleeping, thoughts about death, and guilt. Each item was evaluated by respondents using a 5 -point Likert scale, with 0 indicating "not at all" and 4 indicating "strongly agree", and a high score represented a greater degree of distress pertaining to the respondent's mental health. Cronbach's $\alpha$ was between $0.67 \sim 0.89$ at the time of the tool's development, and it was 0.98 for this study.

\section{Data collection}

Data collection was conducted between May 1, 2019, and June 1, 2020, after receiving approval from the institutional review board at S Hospital. When a patient was admitted to the hospice and palliative care ward, a researcher explained the purpose of the study, needs, and data collection methods to the patient and their caregivers. Once a potential participant understood the purpose of the study and voluntarily consented to participate, a nurse in charge screened for delirium using the K-DRS-98. When the patient was confirmed to have delirium by the medical staff in charge, the patient's family members were given questionnaires, which were returned within 24 hours of admission. Most questionnaires were completed in about 10 to 15 minutes, and we presented participants with small tokens of appreciation.

In order to prevent errors when nurses and medical staff made diagnoses regarding delirium, the K-DRS-98 evaluation instructions were distributed among the staff and the researchers conducted multiple educational sessions and training, then confirmed interrater reliability. Fless's kappa coefficient was 0.92.

\section{Ethical considerations}

This study was approved by the institutional review board of S Hospital (Approval number: KC19QESI0386). A researcher provided a verbal explanation of the purpose of the study and methods for participation to patients and their families in person. Moreover, participants were assured that they could withdraw their consent at any time if they felt they did not want to participate in the study, that their questionnaires would only be used for research purposes, and that their anonymity would be maintained. The survey was only completed after written consent was received following a verbal explanation of the study. Once collected, data were assigned a unique serial number to render the participant unidentifiable. The contents of the survey results were numerically processed in an electronic system to maintain confidentiality. 


\section{Data analysis}

Data analysis was performed using SPSS. The following analyses were conducted:

1. Demographic and clinical characteristics of patients and families, as well as characteristics related to delirium, were analyzed to determine real numbers, percentages, averages, and standard deviation.

2. Family members' knowledge, caregiving performance, stress levels, and mental health pertaining to delirium were analyzed to determine real numbers, percentages, averages, and standard deviation.

3. Differences in knowledge, caregiving performance, stress levels, and mental health pertaining to delirium according to the characteristics of patients and families were analyzed using the chi-square test, t-test, ANOVA, and Scheffé test.

\section{RESULTS}

\section{Demographic and clinical characteristics of the delirium group and the non-delirium group}

In terms of sex, $52.1 \%$ of the delirium group was male, while $60.2 \%$ of the non-delirium group was female. The majority of people were 65 or older in both groups, with $69.8 \%$ in the delirium group and $61.4 \%$ in the non-delirium group, and there was no significant difference between the two groups $(\mathrm{P}=0.055$, $\mathrm{P}=0.169)$. The most common type of primary cancer for the

Table 1. Demographic and Clinical Characteristics of Patients ( $N=267)$.

\begin{tabular}{|c|c|c|c|c|c|}
\hline \multirow{2}{*}{ Characteristics } & \multirow{2}{*}{ Categories } & \multirow{2}{*}{$\begin{array}{c}\text { Delirium }(n=96) \\
n(\%) \text { or mean } \pm S D\end{array}$} & \multirow{2}{*}{$\begin{array}{c}\text { Non-delirium }(n=171) \\
n(\%) \text { or mean } \pm S D\end{array}$} & \multirow{2}{*}{$t / \chi^{2}$} & \multirow{2}{*}{$\mathrm{P}$} \\
\hline & & & & & \\
\hline \multirow[t]{2}{*}{ Sex } & Male & $50(52.1)$ & $68(39.8)$ & 3.78 & 0.055 \\
\hline & Female & $46(47.9)$ & $103(60.2)$ & & \\
\hline \multirow[t]{2}{*}{ Age (yr) } & $<65$ & $29(30.2)$ & $66(38.6)$ & 1.88 & 0.169 \\
\hline & $\geq 65$ & $67(69.8)$ & $105(61.4)$ & & \\
\hline \multirow[t]{14}{*}{ Cancer types } & Bronchus/lung & $13(13.5)$ & $26(15.2)$ & $20.84 *$ & 0.076 \\
\hline & Liver/bile duct & $14(14.6)$ & $22(12.9)$ & & \\
\hline & Stomach & $11(11.5)$ & $30(17.5)$ & & \\
\hline & Colon & $13(13.5)$ & $21(12.3)$ & & \\
\hline & Pancreas & $11(11.5)$ & $22(12.9)$ & & \\
\hline & Breast & $7(7.3)$ & $14(8.2)$ & & \\
\hline & Head \& neck & $6(6.3)$ & $0(0)$ & & \\
\hline & Prostate & $1(1.0)$ & $2(1.2)$ & & \\
\hline & Leukemia & $3(3.1)$ & $2(1.2)$ & & \\
\hline & Esophagus & $1(1.0)$ & $4(2.3)$ & & \\
\hline & Brain tumor & $3(3.1)$ & $0(0)$ & & \\
\hline & Uterus/ovary & $5(5.2)$ & $12(7.0)$ & & \\
\hline & Other solid & $5(5.2)$ & $11(6.4)$ & & \\
\hline & Other hematological cancer & $2(2.1)$ & $5(2.9)$ & & \\
\hline PPS (\%) & & $37.50 \pm 8.34$ & $50.18 \pm 8.57$ & -11.71 & 0.000 \\
\hline \multirow[t]{3}{*}{ Mental status } & Alert & $13(13.5)$ & 153 (89.5) & 152.26 & 0.000 \\
\hline & Drowsy & $73(76.0)$ & $18(10.5)$ & & \\
\hline & Stupor & $10(10.4)$ & $0(0)$ & & \\
\hline \multirow[t]{2}{*}{ Delirium score } & K-DRS-98 severity score & $25.48 \pm 5.52$ & $4.33 \pm 3.57$ & 33.77 & 0.000 \\
\hline & K-DRS-98 total score & $29.58 \pm 5.88$ & $6.32 \pm 4.14$ & 34.28 & 0.000 \\
\hline \multirow[t]{3}{*}{ Subtype of delirium } & Hypoactive & $31(32.3)$ & & & \\
\hline & Hyperactive & $11(11.5)$ & & & \\
\hline & Mixed & $54(56.3)$ & & & \\
\hline
\end{tabular}

PPS: palliative performance status, K-DRS-98: Korean version of the Delirium Rating Scale-Revised-98.

*Fisher exact test. 
delirium group was liver and biliary tract cancer (14.6\%) and stomach cancer for the non-delirium group (17.5\%). No significant difference was found $(\mathrm{P}=0.076)$. The palliative performance scale, which measures one's ability to maintain routine activities, showed a significantly lower result for the delirium group (37.50\%) than the non-delirium group (50.18\%) $(\mathrm{P}=0.000)$. Mental status also showed a significant difference between the two groups, with $76 \%$ of respondents in the delirium group reporting drowsiness and $89.5 \%$ of respondents from the non-delirium group reporting that they were mentally alert $(\mathrm{P}=0.000)$. The most prevalent subtype of delirium in the delirium group was mixed delirium (56.3\%) followed by hypoactive (32.3\%), then hyperactive (11.3\%) (Table 1).

\section{General characteristics and characteristics related to caregiving of family members}

The majority of caregivers were women (64.6\%) as opposed to men (35.4\%), and the average age of participants was 57.8 years old. The most common education level was college or higher $(49.0 \%)$. Caregivers were most often the children (46.9\%) of patients, followed by spouses (40.6\%). The level of support given by other family members had a roughly equal distribution, with $32.2 \%$ of respondents reporting that they received a lot of assistance, $31.3 \%$ reporting that they received average assistance, and 36.5\% reporting that they received a little assistance. The average time spent on caregiving was 22 hours per week. The most common duration of caregiving was 13 to 36 months (33.3\%). Regarding health conditions, the highest proportion of participants (42.7\%) answered "not healthy but does not affect everyday life", followed by those who answered "just fine" (37.5\%). In total, $90.6 \%$ of participants reported that they had never received any education pertaining to delirium (Table 2).

\section{Families' knowledge, caregiving performance, stress levels, and mental health pertaining to delirium}

\section{1) Knowledge of caregiving for delirium}

For knowledge of caregiving for delirium, the overall correct answer rate was $53.2 \%$. Broken down by subcategories, the correct answer rate was $41.5 \%$ for knowledge related to the cause of delirium, $65.4 \%$ for knowledge related to the symp-
Table 2. General Characteristics of Family Caregivers ( $N=96)$.

\begin{tabular}{|c|c|c|c|}
\hline Characteristics & Category & $\mathrm{n}(\%)$ & Mean \pm SD \\
\hline \multirow[t]{2}{*}{ Sex } & Male & $34(35.4)$ & \\
\hline & Female & $62(64.6)$ & \\
\hline \multirow[t]{6}{*}{ Age (yr) } & & & $57.78 \pm 12.54$ \\
\hline & $\leq 40$ & $9(9.4)$ & \\
\hline & $41 \sim 50$ & $17(17.7)$ & \\
\hline & $51 \sim 60$ & $30(31.3)$ & \\
\hline & $61 \sim 70$ & $27(28.1)$ & \\
\hline & $\geq 71$ & $13(13.5)$ & \\
\hline \multirow[t]{4}{*}{ Education level } & $\begin{array}{l}\text { Elementary } \\
\text { school or below }\end{array}$ & $5(5.2)$ & \\
\hline & Middle school & $12(12.5)$ & \\
\hline & High school & $32(33.3)$ & \\
\hline & College or higher & $47(49.0)$ & \\
\hline \multirow{4}{*}{$\begin{array}{l}\text { Relationship with } \\
\text { patient }\end{array}$} & Spouse & $39(40.6)$ & \\
\hline & Child & $45(46.9)$ & \\
\hline & Parent & $4(4.2)$ & \\
\hline & Sibling & $8(8.3)$ & \\
\hline \multirow{3}{*}{$\begin{array}{l}\text { Assistance } \\
\text { by other } \\
\text { caregivers }\end{array}$} & A lot of assistance & $31(32.2)$ & \\
\hline & Average assistance & $30(31.3)$ & \\
\hline & Little assistance & $35(36.5)$ & \\
\hline $\begin{array}{l}\text { Time spent on } \\
\text { caregiving } \\
\text { (hours per } \\
\text { week) }\end{array}$ & & & $22.02 \pm 29.84$ \\
\hline \multirow{4}{*}{$\begin{array}{l}\text { Duration of } \\
\text { caregiving } \\
\text { (mo) }\end{array}$} & $\leq 6$ & $28(29.2)$ & \\
\hline & $7 \sim 12$ & 19 (19.8) & \\
\hline & $13 \sim 36$ & $32(33.3)$ & \\
\hline & $>36$ & $17(17.7)$ & \\
\hline \multirow[t]{4}{*}{ Health status } & Very healthy & $12(12.5)$ & \\
\hline & Just fine & $36(37.5)$ & \\
\hline & $\begin{array}{l}\text { Not healthy but } \\
\text { does not affect } \\
\text { everyday life }\end{array}$ & $41(42.7)$ & \\
\hline & Notaffected & $7(7.3)$ & \\
\hline \multirow{2}{*}{$\begin{array}{l}\text { Experience } \\
\text { of delirium } \\
\text { education }\end{array}$} & Yes & $9(9.4)$ & \\
\hline & No & 87 (90.6) & \\
\hline
\end{tabular}

toms of delirium, and $51.7 \%$ for knowledge on caregiving for delirium. The following items had the highest answer rates: "the top priority of caregiving is to keep the patient safe and support her/him" (84.4\%), "sleep patterns become irregular in a delirious state" (80.2\%), "serious pre-existing conditions may increase the risk of developing delirium" (79.2\%), and "a patient may talk deliriously or act aggressively" (79.2\%). The questions that showed the lowest correct answer rate were "restraint belts help control symptoms" (16.7\%), "prescription glasses for elderly patients with poor eyesight may prevent 
them from developing delirium" (21.9\%), and "the primary treatment for delirium is medication" (26.0\%) (Table 3).

\section{2) Performance of caregiving for delirium}

The total average score for the performance of caregiving for delirium was $2.60 \pm 0.50$ points. Broken down by subcategory, the average score for items pertaining only to caregiving for

Table 3. Delirium-Related Knowledge of Family Caregivers ( $N=96$ ).

\begin{tabular}{|c|c|c|c|c|c|}
\hline \multirow{2}{*}{ Category } & \multirow{2}{*}{ Item } & Yes & No & Do notknow & Correct answer \\
\hline & & $\mathrm{n}(\%)$ & $\mathrm{n}(\%)$ & $\mathrm{n}(\%)$ & $\mathrm{n}(\%)$ \\
\hline \multirow[t]{8}{*}{ Cause } & 1. Delirium is related to brain disease & $38(39.6)$ & $42(39.6)$ & $16(16.7)$ & $38(39.6)$ \\
\hline & $\begin{array}{l}\text { 2. Serious pre-existing conditions may increase the risk of } \\
\text { developing delirium }\end{array}$ & $76(79.2)$ & $9(9.4)$ & $11(11.5)$ & $76(79.2)$ \\
\hline & $\begin{array}{l}\text { 3. Delirium is related to the mental condition of the patient } \\
\text { before hospitalization }\end{array}$ & $33(34.4)$ & $45(46.9)$ & $18(18.8)$ & $33(34.4)$ \\
\hline & $\begin{array}{l}\text { 4. Alcohol-dependent patients become more vulnerable to } \\
\text { delirium when they stop drinking during hospitalization }\end{array}$ & $42(43.8)$ & $28(29.2)$ & $26(27.1)$ & $42(43.8)$ \\
\hline & 5. Deteriorated vision or hearing may cause delirium & $27(28.1)$ & $35(36.5)$ & $34(35.4)$ & $27(28.1)$ \\
\hline & $\begin{array}{l}\text { 6. Delirium is related to one's immobile posture caused by } \\
\text { medical equipment attached to body }\end{array}$ & $28(29.2)$ & $36(37.5)$ & $32(33.3)$ & $28(29.2)$ \\
\hline & 7. Delirium is related to being away from family & $35(36.5)$ & $41(42.7)$ & $20(20.8)$ & $35(36.5)$ \\
\hline & Subtotal & & & & $39.86(41.5)$ \\
\hline \multirow[t]{9}{*}{ Symptom } & 8. Delirium develops in an acute form & $52(54.2)$ & $21(21.9)$ & $23(24.0)$ & $52(54.2)$ \\
\hline & 9. Patient may not recognize others & $58(60.4)$ & $24(25.0)$ & $13(13.5)$ & $58(60.4)$ \\
\hline & 10. Symptoms get worse at night & $60(62.5)$ & $18(18.8)$ & $18(18.8)$ & $60(62.5)$ \\
\hline & 11. Patient may feel anxious or scared in a delirious state & $42(43.8)$ & $16(16.7)$ & $38(39.6)$ & $42(43.8)$ \\
\hline & 12. Patient may talk deliriously or act aggressively & $76(79.2)$ & $11(11.5)$ & $9(9.4)$ & $76(79.2)$ \\
\hline & $\begin{array}{l}\text { 13. Patient may be uncooperative in medical procedures, } \\
\text { pulling tubes or other attachments from the body }\end{array}$ & $66(68.8)$ & $21(21.9)$ & $9(9.4)$ & $66(68.8)$ \\
\hline & 14. Sleep patterns become irregular in a delirious state & $77(80.2)$ & $6(6.3)$ & $13(13.5)$ & $77(80.2)$ \\
\hline & $\begin{array}{l}\text { 15. Patients may experience slow movement, a drawl, or } \\
\text { drowsiness }\end{array}$ & $71(74.0)$ & $11(11.5)$ & $14(14.6)$ & $71(74.0)$ \\
\hline & Subtotal & & & & $62.75(65.4)$ \\
\hline \multirow[t]{11}{*}{ Caregiving } & $\begin{array}{l}\text { 16. The top priority of caregiving is to keep the patient safe } \\
\text { and support her/him }\end{array}$ & $81(84.4)$ & $6(6.3)$ & $9(9.4)$ & $81(84.4)$ \\
\hline & $\begin{array}{l}\text { 17. Optimal caregiving may prevent patients from } \\
\text { developing delirium }\end{array}$ & $33(34.4)$ & $34(35.4)$ & $29(30.2)$ & $33(34.4)$ \\
\hline & $\begin{array}{l}\text { 18. Encouraging patients to sit in a chair or move around } \\
\text { rather than staying in bed helps prevent delirium }\end{array}$ & $61(63.5)$ & $9(9.4)$ & $26(27.1)$ & $61(63.5)$ \\
\hline & 19. Sufficient fluid intake helps prevent delirium & $51(53.1)$ & $9(9.4)$ & $36(37.5)$ & $51(53.1)$ \\
\hline & $\begin{array}{l}\text { 20. Reminding elderly patients of acquaintances, places, or } \\
\text { times helps them recover from delirium }\end{array}$ & $64(66.7)$ & $14(14.6)$ & $18(18.8)$ & $64(66.7)$ \\
\hline & $\begin{array}{l}\text { 21. Reminding patients of seasons and providing a calendar } \\
\text { or a clock help manage delirium }\end{array}$ & $70(72.9)$ & $9(9.4)$ & $17(17.7)$ & $70(72.9)$ \\
\hline & $\begin{array}{l}\text { 22. Short and simple sentences should be used when } \\
\text { speaking to patients with delirium }\end{array}$ & $74(77.1)$ & $10(10.4)$ & $12(12.5)$ & $74(77.1)$ \\
\hline & $\begin{array}{l}\text { 23. Prescription glasses for elderly patients with poor } \\
\text { eyesight may prevent them from developing delirium }\end{array}$ & $21(21.9)$ & $19(19.8)$ & $56(58.3)$ & $21(21.9)$ \\
\hline & 24. Restraint belts help control symptoms & $42(43.8)$ & $16(16.7)$ & $38(39.6)$ & $16(16.7)$ \\
\hline & 25. The primary treatment for delirium is medication & $31(32.3)$ & $25(26.0)$ & $40(41.7)$ & $25(26.0)$ \\
\hline & Subtotal & & & & $49.60(51.7)$ \\
\hline Total & & & & & $51.08(53.2)$ \\
\hline
\end{tabular}


patients without delirium was $2.16 \pm 0.95$ points and $2.84 \pm$ 1.01 points for items only pertaining to caregiving for patients with delirium. The caregiving duties with the highest performance score were "I perform a range of motion exercises for the patient's joints three times daily if she/he is kept in restraint belts" $(3.64 \pm 0.77)$ followed by "I let the patient listen to the radio for her/his cognitive stimulation" and "I try activities (e.g., word games) that provide cognitive stimulation for the patient" (3.59 \pm 0.79$)$, then "I let the patient wear a hearing aid or use communication tools (e.g., word cards) if she/he has a hearing problem" $(3.35 \pm 1.10)$. The caregiving duties with the lowest performance score were "I try not to make unnecessary noise" (1.67 \pm 0.84$)$, "I listen carefully to the patient" (1.82 \pm
0.95), and "I try to provide the patient with a single nighttime regimen in order not to interrupt her/his sleep" $(2.04 \pm 1.03)$ (Table 4).

\section{3) Delirium-related stress}

The average score for delirium-related stress was $39.88 \pm$ 16.55 points. Broken down by subcategory, the average score for patient-related stress was $44.32 \pm 28.98$ points, $44.21 \pm$ 30.15 points for duty-related stress, and $22.35 \pm 25.03$ points for interpersonal relationship-related stress. The items with the highest scores for stress were "my techniques or experience caring for a patient with delirium are insufficient" (67.19 \pm 29.05), "my knowledge of information pertaining to delirium

Table 4. Caregiving Performance Related to Delirium of Family Caregivers ( $N=96)$.

\begin{tabular}{|c|c|c|}
\hline Category & Item & Mean $\pm S D$ \\
\hline \multirow{9}{*}{$\begin{array}{l}\text { Caregiving for patients } \\
\text { without delirium }\end{array}$} & 1. I often talk to the patient about dates, times or places & $2.54 \pm 0.78$ \\
\hline & 2. I explain to the patient what procedures are being done & $2.20 \pm 0.85$ \\
\hline & 3. I listen carefully to the patient & $1.82 \pm 0.95$ \\
\hline & 4. I only have necessary conversations with a quiet voice & $2.24 \pm 1.05$ \\
\hline & 5. I keep lights on at night & $2.55 \pm 1.15$ \\
\hline & 6. I try to provide the patient with a single nighttime regimen in order not to interrupt her/his sleep & $2.04 \pm 1.03$ \\
\hline & 7. I properly reposition the patient in bed to prevent skin damage & $2.21 \pm 0.98$ \\
\hline & $\begin{array}{l}\text { 8. I try not to make unnecessary noise (e.g., sounds while walking, throwing away trash, phone- } \\
\text { ringing, etc.) }\end{array}$ & $1.67 \pm 0.84$ \\
\hline & Subtotal & $2.16 \pm 0.95$ \\
\hline \multirow{18}{*}{$\begin{array}{l}\text { Caregiving for patient with } \\
\text { delirium }\end{array}$} & 9. I let the patient listen to the radio for her/his cognitive stimulation & $3.59 \pm 0.79$ \\
\hline & 10. I call the patient by her/his name & $3.02 \pm 1.16$ \\
\hline & 11. I provide patient stimuli about time and place by using clocks, calendars, etc. & $2.82 \pm 1.04$ \\
\hline & 12. I speak to the patient using detailed, short and simple sentences & $2.15 \pm 0.91$ \\
\hline & 13. I ask other family members to bring objects that are familiar or meaningful to patient & $2.86 \pm 1.06$ \\
\hline & $\begin{array}{l}\text { 14. I try to make the patient understand it is not real when she/he experiences visual hallucinations } \\
\text { (e.g., when she/he sees things) }\end{array}$ & $2.41 \pm 1.06$ \\
\hline & 15. I give the patient massages & $2.43 \pm 1.02$ \\
\hline & 16. I let the patient wear glasses if she/he has visual difficulties & $3.23 \pm 1.04$ \\
\hline & $\begin{array}{l}\text { 17. I let the patient wear a hearing aid or use communication tools (e.g., word cards) if she/he has } \\
\text { a hearing problem }\end{array}$ & $3.35 \pm 1.10$ \\
\hline & 18. Itry activities (e.g., word games) that provide cognitive stimulation for the patient & $3.59 \pm 0.79$ \\
\hline & $\begin{array}{l}\text { 19. I perform a range of motion exercises for the patient's joints three times daily if she/he is kept } \\
\text { in restraint belts }\end{array}$ & $3.64 \pm 0.77$ \\
\hline & 20. I clean up the patient's room so unnecessary objects will not be around & $2.15 \pm 1.05$ \\
\hline & 21. I do not speak in a commanding tone & $2.77 \pm 1.13$ \\
\hline & 22. I try not to use restraint belts if possible & $2.89 \pm 1.17$ \\
\hline & 23. I encourage the patient's family to stay around to promote emotional support & $2.18 \pm 1.05$ \\
\hline & 24. I keep dim lights on during the night to create a safe environment & $2.20 \pm 1.07$ \\
\hline & 25. I encourage the patient to wake up early and move around as much as possible & $3.05 \pm 0.96$ \\
\hline & Subtotal & $2.84 \pm 1.01$ \\
\hline Total & & $2.60 \pm 0.50$ \\
\hline
\end{tabular}


is insufficient" (64.82 \pm 28.03$)$, and "the patient is in pain" (63.39 \pm 24.80$)$. The items with the lowest scores for stress were "nurses interfere with or do not trust my caregiving" (9.79 \pm 18.35 ), "I think healthcare provider does not immediately give the patient a sedative injection" (15.63 \pm 21.27$)$, and "the patient's other family members or guardians interfere with or do not trust my caregiving" $(17.40 \pm 25.93)$ (Table 5).

\section{4) Mental health}

The average score for family caregivers' mental health status was $1.96 \pm 0.70$ points. Broken down by subcategory, additional items had the highest average score $(2.28 \pm 0.84)$ despite not being one of the nine main categories that examined systemic issues. The next highest score was found for depression (2.27 \pm 0.84 ), and then obsessive-compulsive behavior (2.24 \pm $0.85)$. The category with the lowest average score was phobic anxiety $(1.60 \pm 0.81)$, followed by paranoid ideation (1.62 \pm $0.72)$, and psychoticism (1.63 \pm 0.68$)$ (Table 6).

\section{Differences in delirium-related knowledge, caregiving performance, stress levels, and mental health based on the demographic characteristics of family caregivers}

Knowledge of caregiving for delirium showed a difference

Table 6. Mental Health of Family Caregivers ( $N=96)$.

\begin{tabular}{lcc}
\hline \multicolumn{1}{c}{ Category } & (Item count) & Mean \pm SD \\
\hline Somatization & $(12)$ & $2.00 \pm 0.74$ \\
Obsessive-compulsive & $(10)$ & $2.24 \pm 0.85$ \\
Interpersonal sensitivity & $(9)$ & $1.89 \pm 0.80$ \\
Depression & $(13)$ & $2.27 \pm 0.84$ \\
Anxiety & $(10)$ & $1.96 \pm 0.75$ \\
Hostility & $(6)$ & $1.85 \pm 0.82$ \\
Phobic anxiety & $(7)$ & $1.60 \pm 0.81$ \\
Paranoid ideation & $(6)$ & $1.62 \pm 0.72$ \\
Psychoticism & $(10)$ & $1.63 \pm 0.68$ \\
Additional items & $(7)$ & $2.28 \pm 0.84$ \\
Total & $(90)$ & $1.96 \pm 0.70$ \\
\hline
\end{tabular}

Table 5. Stress of Family Caregivers Related to Caregiving for Delirium ( $N=96$ ).

\begin{tabular}{|c|c|c|}
\hline Category & Item & Mean \pm SD \\
\hline \multirow[t]{8}{*}{ Patient-related } & 1. The patient is not cooperative due to her/his instability & $52.55 \pm 26.26$ \\
\hline & 2. The patient refuses food or medication & $34.95 \pm 31.83$ \\
\hline & 3. I am afraid the patient might fall from bed and be injured & $59.53 \pm 29.86$ \\
\hline & 4. The patient's screaming or violent behavior makes me distressed & $35.83 \pm 32.37$ \\
\hline & 5. I am afraid the patient might pull out any tubes or her/his IV & $45.94 \pm 34.25$ \\
\hline & 6. The patient is in pain & $63.39 \pm 24.80$ \\
\hline & 7. The patient swears at me & $18.07 \pm 23.52$ \\
\hline & Subtotal & $44.32 \pm 28.98$ \\
\hline \multirow[t]{10}{*}{ Duty-related } & 8. I am afraid of getting injured during caregiving & $22.29 \pm 26.14$ \\
\hline & 9. I cannot leave the patient even for a minute & $60.31 \pm 29.57$ \\
\hline & $\begin{array}{l}\text { 10. It is very hard to apply restraint belts on the patient by myself while she/he shows violent } \\
\text { behavior }\end{array}$ & $30.94 \pm 33.66$ \\
\hline & 11. Delirium symptoms get worse at night, so I cannot sleep & $51.20 \pm 34.52$ \\
\hline & 12. I keep following the patient around so that he/her does not run away & $27.29 \pm 30.45$ \\
\hline & 13. My knowledge of information pertaining to delirium is insufficient & $64.82 \pm 28.03$ \\
\hline & 14. My techniques or experience caring for a patient with delirium are insufficient & $67.19 \pm 29.05$ \\
\hline & 15. I am afraid that problems might occur with the patient, for which I will be responsible & $23.85 \pm 29.68$ \\
\hline & 16. It is difficult to communicate with the patient & $50.00 \pm 30.26$ \\
\hline & Subtotal & $44.21 \pm 30.15$ \\
\hline \multirow[t]{5}{*}{$\begin{array}{l}\text { Interpersonal relationship- } \\
\text { related }\end{array}$} & $\begin{array}{l}\text { 17. I feel uncomfortable that other patients, families or guardians might be upset when the } \\
\text { patient for whom I provide care makes noises and shows violent behaviors }\end{array}$ & $46.56 \pm 34.58$ \\
\hline & 18. The patient's other family members or guardians interfere with or do not trust my caregiving & $17.40 \pm 25.93$ \\
\hline & 19. Nurses interfere with or do not trust my caregiving & $9.79 \pm 18.35$ \\
\hline & 20. I think healthcare providers do not immediately give the patient a sedative injection & $15.63 \pm 21.27$ \\
\hline & Subtotal & $22.35 \pm 25.03$ \\
\hline Total & & $39.88 \pm 16.55$ \\
\hline
\end{tabular}


based on health condition $(\mathrm{F}=4.36, \mathrm{P}=0.006)$ and experience of delirium education $(\mathrm{t}=-2.71, \mathrm{P}=0.008)$. These results indicate that family caregivers with an average health condition had better knowledge of caregiving for delirium than family caregivers with very good health. In addition, family caregivers without delirium education had a better knowledge of caregiving for delirium than family caregivers who had experienced education pertaining to delirium.

The performance of caregiving for delirium showed differences depending on health condition $(\mathrm{F}=5.98, \mathrm{P}=0.001)$ and the subtype of delirium ( $\mathrm{F}=3.30, \mathrm{P}=0.041)$. These results indicate that family caregivers who answered "just fine" or "not healthy but does not affect everyday life" for their health condition performed better at caregiving for delirium than families who answered "very healthy." The family caregivers of patients who suffered from hyperactive delirium also performed better at caregiving for delirium than caregivers of mixed delirium patients.

Delirium-related stress differed according to the level of caregiving support from other family members $(F=3.63$, $\mathrm{P}=0.030$ ). Although a post-hoc analysis did not show a statistically significant difference, families who received more assistance experienced less stress related to caregiving.

Mental health status differed according to a respondent's reported health status $(\mathrm{F}=2.81, \mathrm{P}=0.044)$. Although a posthoc analysis did not show a statistically significant difference, family caregivers who answered "very healthy" for their health condition still appeared to have a better mental health status than those who answered otherwise (Table 7).

\section{DISCUSSION}

This study aimed to examine the knowledge, caregiving performance, stress levels, and mental health pertaining to delirium of family caregivers of terminal cancer patients who suffered from delirium and were admitted to a hospice ward. This study was intended to provide data as a fundamental resource for developing educational materials to raise awareness of caregiving for delirium and improve family caregivers' ability to treat this condition.

This study showed that the prevalence of delirium among terminal cancer patients was $23.5 \%$. This figure is higher than that of a study that examined patients admitted to intensive care units, which showed a prevalence of $15.3 \%$ for delirium [21], and lower than that of a study that examined terminal cancer patients, which showed a prevalence of $57.7 \%$ [22]. Such discrepancies could be due to having excluded patients who were admitted to end-of-life care programs, who made up $28.5 \%$ of potential participants, from this study. As has been demonstrated, delirium is common among terminal cancer patients and can result in severe complications, and there tends to be no education related to delirium given in advance to patients or their families. The findings of this study showed that only nine family caregivers (9.4\%) out of the 96 respondents had received education on delirium, and a study by Oh [6] reported that only $1.5 \%$ of caregivers had received education on delirium. These findings indicate that the communication of accurate and detailed information pertaining to delirium through education initiatives is imperative, and the development of educational programs that can be integrated into the clinical field is necessary.

The correct answer rate of family caregivers for deliriumrelated knowledge was $53.2 \%$. This is similar to the rate found by $\mathrm{Oh}$ [6] in a study examining family members of elderly patients (55.1\%). It is, however, lower than the rate found by Jeong [18] in a study of professional caregivers (68.7\%) and the rate found in studies of nursing professionals (68.4 73\%) $[23,24]$. While more than $90 \%$ of caregivers and nurses in those studies had received education related to delirium, less than $10 \%$ of family caregivers had done so. This shows the necessity of developing a proper training program to improve family caretakers' knowledge of delirium. In addition, the items that showed the lowest correct answer rate for knowledge of caretaking for delirium were "restraint belts help control symptoms" (16.7\%) and "the primary treatment for delirium is medication" (26.0\%), and the results were similar for the studies of caregivers. These types of misconceptions could lead to improper caregiving, such as attempts to hastily alleviate symptoms through medication or the discretionary use of restraint belts, which in turn can exacerbate the aggressive behaviors of patients by increasing their risk of falling. Inappropriate care could also result in functional deficiencies and worsen the prognosis of the patient's disease. Therefore, caregiving practices for delirium should be guided using education 


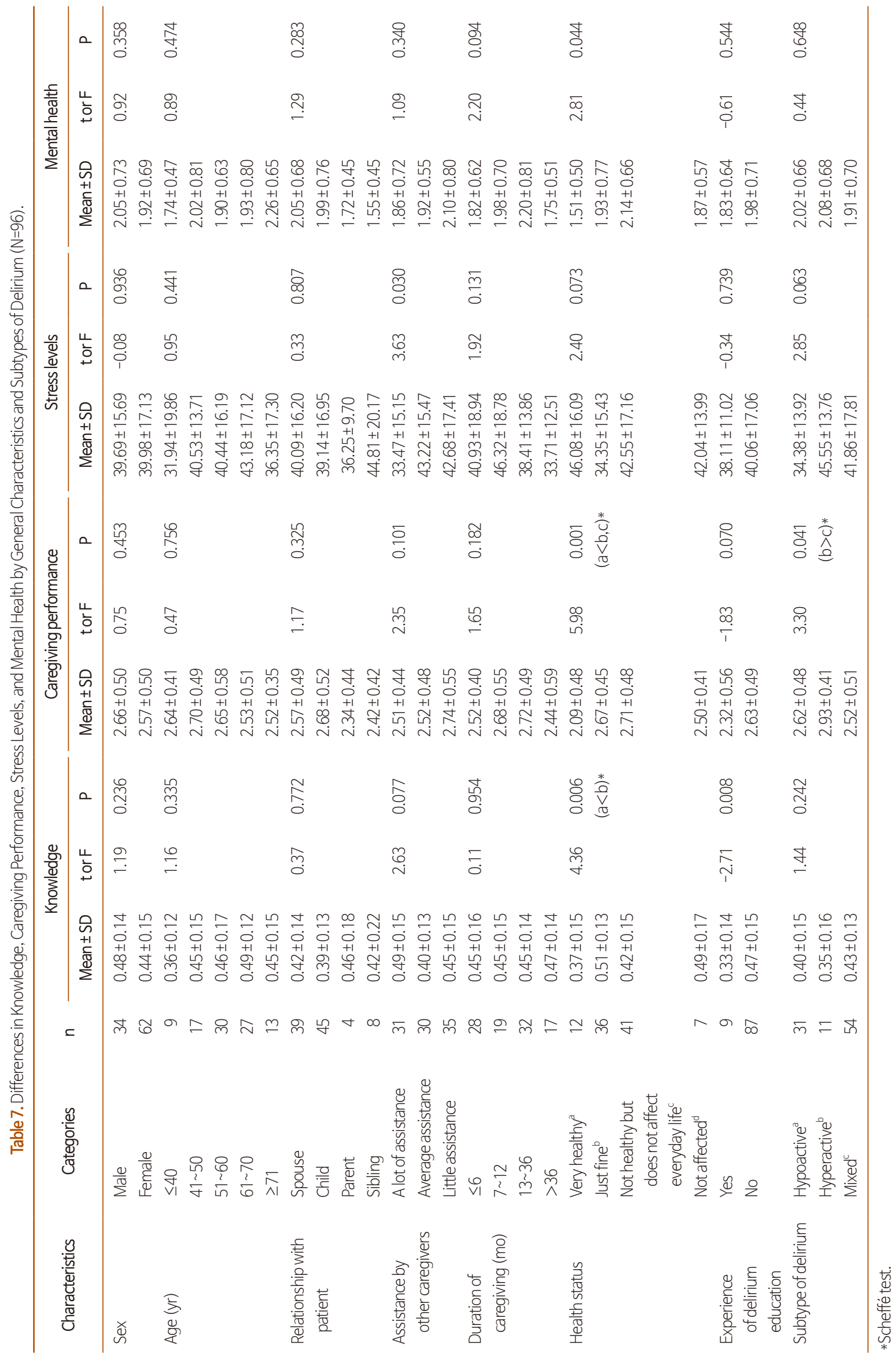


that primarily addresses popular misconceptions.

The average score for performance of caregiving for delirium by family caregivers was $2.60 \pm 0.50$. On a 100 -point scale, the average score for caregiving performance for delirium was approximately $65 \%$ for family caregivers. Since no study has yet set a precedent for patients' family members' scores, this result was compared to that of a study of professional caregivers [18], who had an average score of $3.06 \pm 0.47$ points $(76.5 \%$ on a 100-point scale), showing a higher caregiving performance score than in this study. This result could be due to caregivers being better informed or more experienced in caregiving for delirium than family members of terminal cancer patients. In addition, family members' caregiving performance showed different trends than that of professional caregivers when each question was examined. Family members scored lower in the environmental management category than professional caregivers, showing a tendency not to lower unnecessary noise or remove unnecessary articles from patients' rooms, and scoring higher for cognitive stimulation activities. Professional caregivers tend to perform fewer cognitive stimulation activities since they tend to be more concerned about potential damages and the impact on patients from assistive devices such as glasses or hearing aids. Family members, however, believed that cognitive stimulation activities were routine in daily caregiving, not necessarily recognizing or being aware of the need for them. Family members' low scores for creating a safe and comfortable environment for patients likely resulted from their lack of knowledge of or experience with basic caregiving activities. Therefore, education on caregiving for delirium targeted to family members needs to include fine details ranging from precautionary caregiving before the onset of delirium to environment management and cognitive stimulation activities without being too overwhelming or difficult to comprehend.

The average score for delirium-related stress experienced by family caregivers was $39.88 \pm 16.55$ points. This figure is significantly lower than the scores for delirium-related stress experienced by caregivers in Jeong's [18] study, which showed an average score of 62.70, and Suh and Yoo's [25] study of intensive care unit nurses, which showed an average score of 63.92 points. This result could be due to the positive impact of the supportive atmosphere provided by the multidisciplinary team in a hospice ward, including volunteers and spiritual care providers, which other hospital departments typically lack. This hypothesis is supported by the particular questions that participants gave an average score of 20 points or lower, including "nurses interfere with or do not trust my caregiving", "I think healthcare providers do not immediately give the patient a sedative injection", and "the patient's other family members or guardians interfere with or do not trust my caregiving." However, family members tended to have substantially higher scores for stress when it came to questions related to lacking sufficient knowledge and experience (64.82, 67.19 points, respectively). This result indicates that family caregivers' stress increases since they are not equipped with sufficient knowledge or techniques to respond appropriately to patients with delirium. Therefore, education to alleviate the burden of caregiving, as well as stress sustained by family caregivers, is necessary.

The mental health of family caregivers showed the highest scores in the additional questions category, followed by depression and obsessive-compulsive behavior, with scores for phobic anxiety being the lowest. This result is commensurate with that of a study by Oh and Chun [26], which examined family caregivers of patients with chronic conditions. A study by Cho and Oh [27] on the family members of cancer patients who underwent surgical treatment also showed similar findings, as obsessive-compulsive behavior had the highest score while phobic anxiety had the lowest. This could be a result of the inherent characteristics of hospice wards. Since patients' conditions tend to deteriorate with the onset of advanced delirium, family members' depressive tendencies may increase in turn. Moreover, most of the highest-scoring questions within the additional items category were related to sleep disturbances. Because patients' delirium symptoms likely tended to become more severe at night, family caregivers may have been prevented from getting adequate sleep. Therefore, the results for mental health demonstrate that supportive nursing such as providing rest for family caregivers is necessary for family caregivers who get exhausted from taking care of patients through the night.

This study examined differences in delirium-related knowledge, caregiving performance, stress levels, and mental health of family caregivers according to demographic characteristics, caregiving characteristics, and delirium subtypes of patients. As a result, this study found that the knowledge of caregiving for 
delirium was better among family members who had not received education on delirium than among family members who had done so. This result underscores the necessity for practical delirium education and methods of delivery that can improve understanding of delirium. The analysis of stress related to caregiving for delirium based on family characteristics showed that family members who received more caregiving assistance from other family members experienced less stress than family members who received less assistance. This indicates that family members providing care for terminal cancer patients with delirium tend to feel high levels of exhaustion both physically and mentally and need support and aid from other family members. A proper intervention is needed to empathize with family caregivers undergoing stress, provide encouragement and support, and encourage co-operation among other family members to alleviate the stress of family caregivers. The analysis of delirium-related caregiving performance based on delirium subtype showed that the family members of patients with hyperactive delirium had higher scores for caregiving performance than the family members of patients with mixed delirium. This tendency is likely the result of close observation and preparation from doctors who are more educated and $\mathrm{ex}^{-}$ perienced, since hyperactive delirium patients are more inclined to be aggressive and unstable compared to hypoactive and mixed delirium patients. However, there is a limitation in the effective identification of hypoactive delirium due to confusion between depression and sedation from opioids. Therefore, it is suggested that educational programs tailored to each delirium subtype should be developed.

This study will contribute to raising awareness about delirium management for family members who provide care for terminal cancer patients with delirium by examining deliriumrelated knowledge, caregiving performance, stress levels, and mental health, as well as by identifying potential educational directions for improving delirium-related knowledge and caregiving performance. The findings are also expected to serve as a fundamental resource for developing nursing intervention programs that may improve the stress levels and mental health of family members who care for patients with delirium. The results of this study suggest that pre-and post-onset educational programs for family caregivers of patients with delirium should be developed, and follow-up studies should be designed to validate their effectiveness.

\section{CONFLICT OF INTEREST}

No potential conflict of interest relevant to this article was reported.

\section{ORCID}

Mi Hyun Jung, https://orcid.org/0000-0002-1702-1276

Myung-Hee Park, https://orcid.org/0000-0002-7256-8151

Su-Jeong Kim, https://orcid.org/0000-0002-7597-0648

Jeong Ran Ra, https://orcid.org/0000-0002-1403-0193

\section{AUTHOR'S CONTRIBUTIONS}

Conception or design of the work: MHJ, MHP, SJK, JRR. Data collection: MHJ, SJK. Data analysis and interpretation: MHJ, MHP. Drafting the article: MHJ, MHP, SJK, JRR. Critical revision of the article: MHJ, MHP. Final approval of the version to be published: MHJ, MHP.

\section{SUPPLEMENTARY MATERIALS}

Supplementary materials can be found via https://doi. org/10.14475/jhpc.2021.24.2.116.

\section{REFERENCES}

1. American Psychiatric Association.; American Psychiatric Association. DSM-5 Task Force. Diagnostic and statistical manual of mental disorders: DSM-5. 5th ed. Arlington, VA:American Psychiatric Association;2017, c2013. p.596-602.

2. Irwin SA, Rao S, Bower KA, Palica J, Rao SS, Maglione JE, et al. Psychiatric issues in palliative care: Recognition of delirium in patient enrolled in hospice care. Palliat Support Care 2008;6:159-64.

3. Sfera A, Cummings M, Osorio C. Non-neuronal acetylcholine: the missing link between sepsis, cancer, and delirium? Front Med (Lausanne) 
2015;2:56.

4. Lee PJ, Hahm BJ. Pharmacological treatment for delirium in cancer patients. J Korean Neuropsychiatr Assoc 2010;49:20-5.

5. Cohen MZ, Pace EA, Kaur G, Bruera E. Delirium in advanced cancer leading to distress in patients and family caregivers. J Palliat Care 2009;25:164-71.

6. Oh HY. Knowledge, educational needs, and mental health related to delirium of family caregivers of older adults who are hospitalized [master' s thesis]. Seoul: Hanyang Univ.; 2015. Korean.

7. Bull MJ, Boaz L, Sjostedt JM. Family caregivers' knowledge of delirium and preferred modalities for receipt of information. J Appl Gerontol 2016;35:744-58.

8. Mittal V, Muralee S, Williamson D, McEnerney N, Thomas J, Cash M, et al. Review: delirium in the elderly: a comprehensive review. Am J Alzheimers Dis Other Demen 2011;26:97-109.

9. Brajtman S. Helping the family through the experience of terminal restlessness. J Hosp Palliat Nurs 2005;7:73 - 81.

10. Buss MK, Vanderwerker LC, Inouye SK, Zhang B, Block SD, Prigerson HG. Associations between caregiver-perceived delirium in patients with cancer and generalized anxiety in their caregivers. J Palliat Med 2007;10:1083-92.

11. Kim MY, Eun Y. Knowledge, performance and stress about care for delirium in orthopedic hospital nurses. J Muscle Joint Health 2013;20:7280.

12. Kim EH. Relationship between knowledge, stress, and nursing performance about care for delirium in geriatric hospital nurses. JKCHS 2016;4:593-602.

13. Lee JY, Shin JH. Effects of delirium care education on delirium care of Korean-Chinese caregivers caring for elderly postsurgical patients. J Korean Gerontol Nurs 2017;19:194-202.

14. Ko HJ, Youn CH, Chung SE, Kim AS, Kim HM. Risk factors related to development of delirium in hospice patients. J Hosp Palliat Care 2014;17:170-8.

15. Park HS, Kim DS, Bae EH, Kim JR, Seo JH, Yun JM. Retrospective cohort study on the administration of sedative for delirium in terminally III cancer patients and survival time. J Hosp Palliat Care 2016;19:119-26.

16. Trzepacz PT, Baker RW, Greenhouse J. A symptom rating scale for delirium. Psychiatry Res 1988;23:89-97.

17. Lim KO, Kim SY, Lee YH, Lee SW, Kim JL. A validation study for the Korean Version of Delirium Rating scale - Revised-98 (K-DRS-98). J Korean Neuropsychiatr Assoc 2006;45:518-26.

18. Jeong JY. Care aides' knowledge, care performance and care stress of delirium in general hospitals [master's thesis]. Jinju: Gyeongsang National Univ.; 2013. Korean.

19. Kim KI, Won HT, Lee JH, Kim KY. Standardization study of symptom check list-90 in Korea I: Characteristics of normal responses. J Korean Neuropsychiatr Assoc 1978;17:449-58.

20. Derogatis LR, Lipman RS, Covi L. SCL-90: An outpatient psychiatric rating scale-preliminary report. Psychopharmacol Bull 1973;9:13-28.

21. Ahn JS, Oh JY, Park JS, Kim JJ, Park JY. Incidence and procedure-related risk factors of delirium in patients admitted to an intensive care unit. Korean J Psychosom Med 2019;27:35-41.

22. Cho HJ, Kim HK, Kim KK, Kim YI, Suh SY, Cho KH, et al. Delirium in the final weeks of terminally ill cancer patients. Korean J Fam Med 2009;30:285-91.

23. Park HM, Chang MY. Influence of nurse’s knowledge, confidence on nursing performance of delirium. J Health Info Stat 2016;41:359-68.

24. Jang BJ, Yeom HA. Hospice-palliative care nurses' knowledge of delirium, self-efficacy and nursing performance on delirium. Korean J Hosp Palliat Care 2018;21:65-74.

25. Suh HJ, Yoo YS. Intensive care unit nurse's knowledge, nursing performance, and stress about delirium. KJAN 2007:19:55-65.

26. Oh KO, Chun CS. The burden and mental health of family caregiver with chronic mentally ill patients in community. J Korean Acad Psychiatr Ment Health Nurs 2000;9:499-513.

27. Cho EJ, Oh KO. Burden and social support of informal caregivers for cancer patients in postoperative state. J Korean Acad Psychiatr Ment Health Nurs 2008;17:10-8. 